\title{
Biomass Sea-Based Supply Chains and the Secondary Ports in the Era of Decarbonization
}

\author{
Marta Mańkowska ${ }^{1, * \mathbb{D}}$, Michał Pluciński ${ }^{1}$ and Izabela Kotowska ${ }^{2}$ \\ 1 Institute of Management, University of Szczecin, Cukrowa 8, 71-004 Szczecin, Poland; \\ michal.plucinski@usz.edu.pl \\ 2 Faculty of Engineering and Economics of Transport, Maritime University of Szczecin, H. Pobożnego 11, \\ 70-500 Szczecin, Poland; i.kotowska@am.szczecin.pl \\ * Correspondence: marta.mankowska@usz.edu.pl
}

Citation: Mańkowska, M.; Pluciński, M.; Kotowska, I. Biomass Sea-Based Supply Chains and the Secondary Ports in the Era of Decarbonization. Energies 2021, 14 , 1796. https://doi.org/10.3390/ en14071796

Academic Editor:

Ken'ichi Matsumoto

Received: 3 March 2021

Accepted: 22 March 2021

Published: 24 March 2021

Publisher's Note: MDPI stays neutral with regard to jurisdictional claims in published maps and institutional affiliations.

Copyright: (c) 2021 by the authors. Licensee MDPI, Basel, Switzerland. This article is an open access article distributed under the terms and conditions of the Creative Commons Attribution (CC BY) license (https:/ / creativecommons.org/licenses/by/ $4.0 /)$.

\begin{abstract}
One of the tools to attain the goal of climate-neutrality by 2050 by the European Union is increasing the share of renewable energy sources (RESs) in the energy mix of member states. A major part of the future bioenergy mix is to be played by biomass. As many hazards have been pointed out when using forest biomass, particular attention is paid to the potential of agro biomass. However, as agro biomass is sourced mostly locally, the supply may not be sufficient to meet the growing demand. Therefore, international trade (including overseas) might become increasingly important to meet the EU renewable energy targets. In this context, it is seaports that may play a major part in developing biomass supply chains. The main purpose of the article is to fill the research gap by identifying the pros and cons for the development of biomass sea-based supply chains through secondary ports and specifying their relevance from the perspective of major stakeholders in the context of decarbonization processes. The supplementary purpose of the study was the verification of the environmental sustainability of biomass sea-based supply chains through secondary ports versus land transport (carbon footprint). This study applied the single case study method (the case of the secondary port in Szczecin). The case study strategy involved qualitative and quantitative research techniques. Our research study showed that (1) overseas agro biomass (wastes and residues) may become a significant tool in the process of decarbonization of economies that are heavily reliant on coal as a transition fuel and as a stable RES in the structure of the future energy mix; and (2) biomass sea-based supply chains may be an attractive alternative for secondary ports affected by negative outcomes of decarbonization. However, a dedicated biomass terminal would make the secondary ports more attractive for this type of cargo. A biomass terminal may provide sufficient port service efficiency and enable harmonization of deliveries. Additionally, the carbon footprint analysis performed in this study has shown that biomass sea-based supply chains generate lower $\mathrm{CO}_{2}$ emissions than alternative land deliveries.
\end{abstract}

Keywords: renewable energy sources; biomass; supply chains; seaports; overseas sourcing; decarbonization

\section{Introduction}

The European Union (EU) aims to be climate-neutral by 2050 [1]. One of the tools to attain this goal is a substantial reduction of greenhouse gas (GHG) emissions and increasing the share of renewable energy in the energy mix of EU member states [2]. The energy sector is responsible for more than $75 \%$ of GHG emissions in the EU [1]. Directive (EU) $2018 / 2001$ on the promotion of the use of energy from renewable sources [3], amended in December 2018, sets out a new binding target: a minimum 32\% share of renewable energy in the EU by 2030. A major part in the structure of the future bioenergy mix in the EU is to be played by biomass used in combined heat and power production (CHP) [4]. In terms of time to deployment and cost of the solution, biomass is presented as a transition and short/medium-term alternative toward a carbon-neutral energy sector [5]. 
The expected increase in the share of biomass in the EU energy mix means a substantial increase in demand for this resource in the EU by 2030 [6]. At present, forest biomass is still the main source in global bioenergy production [7]. However, research studies have pointed out many hazards when using wood pellets, especially when they have been handled improperly, resulting in serious injuries and even fatalities [8,9]. This inclines users to search for alternatives such as agro biomass waste and residues [10]. Agro biomass in EU countries is sourced mostly locally. The supply of low-cost sustainable biomass in the EU may not be sufficient to meet the growing demand [11]. Therefore, in the case of using up local and low-value sources of biomass, intra-EU and extra-EU trade (including overseas) might become increasingly important to meet renewable energy targets [11-13].

Hoefnagels et al. [13] indicated that the previously established EU renewable energy targets of $20 \%$ by 2020 [14] have already led to changes in the biomass markets and increased volumes of internationally traded biomass. However, the research studies completed hitherto have shown that the international trade in biomass is a significant logistic challenge in terms of transport, handling, and storing this resource [6,15-17]. Research studies have also pointed out that effective logistic and transport solutions in biomass supply chains are particularly needed, especially because most of the increase in biomass use is expected to take place in large heat and power production units [16].

In this context, it is seaports that may play a major part in developing biomass supply chains: they are capable of handling large one-off consignments coming from distant markets and offer specialized additional and added-value services. The engagement of seaports in biomass handling may contribute to designing not only economically effective but also sustainable biomass sea-based supply chains. The mode of transport and distance have significant impacts on life cycle emissions with the lowest sea freight emissions per $\mathrm{km}$ [18].

Additionally, research studies done hitherto have shown that biomass is a cargo that is difficult to handle $[6,15]$. Bottlenecks result mainly from the lack of appropriate technical equipment in seaports-particularly the lack of specialized biomass terminals. This is mainly because despite the rising trend, biomass trading volumes are still small. Consequently, biomass is not an attractive cargo for major hubs. In our opinion, such cargo may be more suitable and prospective for secondary ports, also known as minor, assisting, peripheral, feeder, regional, or small and medium-sized ports [19-22]. Among other factors, as a result of the decarbonization process, these types of seaports are under strong pressure to attract new cargo groups to replace the vanishing ones such as coal [23]. In our opinion, biomass terminals in secondary ports may contribute to the port's development, partially replacing the fading transshipments of coal. They may also form a significant tool to attain the EU 2050 carbon neutrality targets by supporting the decarbonization processes in the economies of member states such as Poland. Around 75\% of the Polish power production industry is still based on coal. Poland is one of the few EU member states that is not going to be on time to achieve the national (reduced) target, being a 15\% share of renewable energy sources (RES) in the gross final energy consumption in 2020 [14,24]. Over recent years, RES development in Poland has been on the rise (the RES share in 2018 was 11.3\% and $11.5 \%$ in 2019). However, according to the forecasts of [25], in 2020, the RES share in the final energy consumption in Poland may rise up to a maximum of $12.2 \%$. The missing total amount of energy from renewable sources in all subsectors in Poland has been estimated to be ca. 2000 ktoe of the gross final energy consumption (23.1 TWh or 83.1 PJ). In our opinion, agro biomass obtained from overseas sources may be a significant tool in the decarbonization of the Polish power sector. On one hand, the major providers of electric power: power plants (PPs) and combined heat and power plants (CHPs) have operable coal-fired boilers that may be adapted to biomass combustion, on the other hand, there are limited possibilities of storing wind and solar energy. Also, there are investments underway and investment plans that involve dedicated biomass boilers.

Issues related to creating biomass sea-based supply chains are addressed in the literature to a very limited extent. The few studies completed so far in that area focus mainly on 
the issue of bottlenecks in handling biomass supply chains at ports or on analyzing sustainable biomass sourcing. There are no complex studies on the development of sustainable biomass sea-based supply chains from the perspective of their participants in the context of decarbonization, and related challenges and opportunities for secondary ports. The main purpose of the studies described in this article is to fill the research gap by identifying the pros and cons for the development of biomass sea-based supply chains through secondary ports and specifying their relevance from the perspective of major stakeholders in the context of decarbonization processes. The supplementary purpose of the study was also verification of the environmental sustainability of biomass sea-based supply chains through secondary ports versus land transport (carbon footprint). The study applied the case study of Poland and the secondary port in Szczecin, one of the main universal Polish seaports located on the Baltic Sea, which meets the criteria of a secondary port. In the course of the study, it was possible to identify managerial implications for stakeholders of biomass sea-based supply chains that involve secondary ports.

This article is a continuation of studies we took up concerning the development of secondary ports as nodal points of circular supply chains [23]. The studies have shown, inter alia, that biomass is one of the major cargoes passing through circular supply chains via secondary ports. The first part of this paper contains the current literature review. Next, the research methodology and sources of data are described. Further sections of this paper present the research findings, followed by a discussion ending with conclusions and managerial implications.

\section{Literature Review}

Beagle and Belmont [18] indicated that international trade and long-distance transportation played an increasingly important role in many biomass supply chains, supporting countries without sufficiently developed national or regional biomass markets. However, Fingerman et al. [26] indicated that meaningful biodiversity protections could only be achieved if sustainability criteria for biomass import were combined with more comprehensive support for sustainable sourcing across biomass industries in exporting regions. Simultaneously, Proskurina et al. [15] indicated that meeting the rigorous criteria of sustainability was one of the bottlenecks in overseas biomass supply.

Research findings have also pointed out that the factors regarding logistics and transport as well as the design and coordination of whole supply chains are critical for ensuring stable biomass supply chains and reducing the overall costs $[17,27]$. The studies $[11,12,15,28,29]$ also pointed out that the adopted logistics and handling of transported biomass was one of the key factors that have an impact on the scale of reduction of GHG emissions over the whole supply chain, which result from biomass (versus fossil fuels) combustion for the purposes of energy production. Simultaneously, Beagle and Belmont [18] showed that biomass sourcing, even from distant markets, resulted in reductions of life cycle emissions compared to electricity generated by coal.

Furthermore, the World Bioenergy Association [17] indicated that the logistics and the mode of long-distance transportation directly varied the structure and way of managing the biomass supply chain. For long-distance and non-time-sensitive transportation of large-scale biomass bulks by sea, the most important issue is securing the biomass supply chain with long-term contracts. In order to enable stable biomass supplies and meet the demand at all times, storage solutions are of great importance. In most cases, biomass has to be stored between different stages of the supply chain and during shorter or longer periods before being used for heat or power generation. This is because demand and supply for biomass (except e.g., wood residues) are characterized by a considerable imbalance $[16,17,30]$. Biomass terminals are facilities that may help to balance the supply and demand to ensure stable flows of resources to customers. Sikanen et al. [16] considered the concept of a biomass terminal as a stopover for biomass between the origin and destination points in the supply chain due to the lack of sufficient space to store or handle the biomass in the storage facility or the plant. The authors have indicated that the need 
for terminals is the highest when the peak seasons of heating and harvests are short and non-simultaneous. Taking into account the temporal fluctuation of demand and supply through the year with different combinations of biomass (by-products and municipal solid waste, primary forest biomass, agricultural crop residues), the strongest fluctuations of demand and supply concern agricultural crop residues and heating plants as end-users. They have also indicated that a terminal is usually established when at least one of the following factors becomes meaningful in biomass procurement: balance factors, resource factors, quality factors, synergistic factors, and legislative factors.

These conditions may to a large extent be met by biomass terminals located in seaports. Among others, Acciaro et al. [31] were right to point out that ports were characterized by the geographical concentration of high energy demand and supply activities because of their proximity to power generation facilities and metropolitan regions, and their functions as central hubs in the transport of raw materials.

The research studies completed hitherto concerning biomass supply chains have focused predominantly on process modeling and optimization [26,32-36]. The studies regarding logistic and transport handling of biomass supplies, in particular in sea-land transport chains, have been tackled only to a limited extent and pertained mainly to wood biomass (wood pellets). Dafnomilis et al. [6], who analyzed imports of wood pellets, and Proskurina et al. [15], who examined the export of wood pellets argued that the most significant bottlenecks identified in biomass sea-based delivery to the EU were related to infrastructural limitations. Biomass is a port cargo that requires specialized handling and dedicated infra- and superstructure. These studies have shown that there is a lack of specialized terminals to handle both imported and exported biomass. Currently, biomass is handled in bulk terminals (coal or ore terminals) using universal equipment. This results in longer handling time and loss of cargo quality. Inappropriate handling of biomass is also connected with risks related to self-heating or dust (no dedusting equipment). There is also a lack of warehouse facilities. The quoted studies also indicate that the lack of investments in biomass terminal infrastructures in ports can be attributed on the one hand to the still small volumes of this type of cargo, and on the other hand, to the relatively small share of port handling costs in the total supply chain costs. The studies stress that the construction of specialized export terminals could considerably shorten the handling time, streamline the logistic chain, and reduce the price of seaborne carriage. At the same time, investing in import terminals may become an important strategic decision in a long-term perspective, in the context of the forecast increase in demand for biomass and the need to transship and store the rising volumes of biomass. Stevens et al. [37] also emphasized the integrative role of seaport authorities in supporting the biomass supply chains. They indicated that port authorities could achieve integration in the biomass supply chain by extending their role and (1) facilitating flows, (2) attracting new flows, (3) executing value-adding activities, (4) developing a bio-industry cluster, and (5) acting as a knowledge center.

Summing up, the studies completed hitherto indicate that the development of biomass sea-based supply chains is affected mainly by sustainability criteria (policy), transport and logistic handling, and storage, especially in the case of agro biomass, in order to balance the fluctuating demand and supply and to stabilize deliveries. The research study described in this paper was aimed at verifying the above-mentioned factors, specifying their relevance and the nature of their impact (pros and cons) from the perspective of various stakeholders of biomass sea-based supply chains.

\section{Materials and Methods}

The single-case-study method [38,39] was applied for the aims of this paper. As pointed out in [39], single-case-based research enables direct observations and interactions that provide insights that are not possible from a distance. The main research techniques used in the case study analysis are presented in Figure 1. 


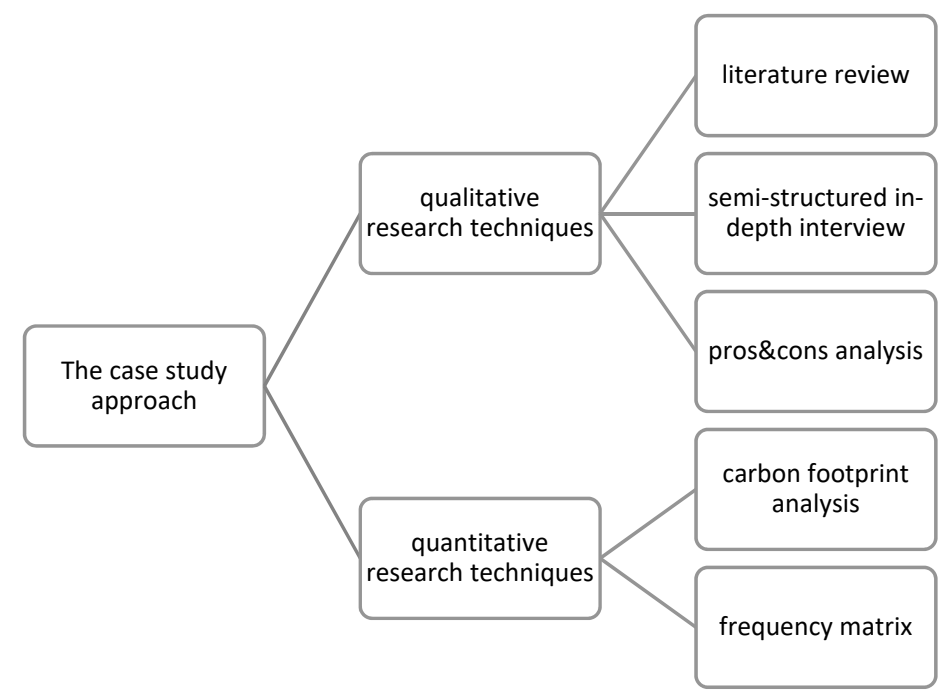

Figure 1. The case study research design.

The main steps of the overall research process are presented in Figure 2.
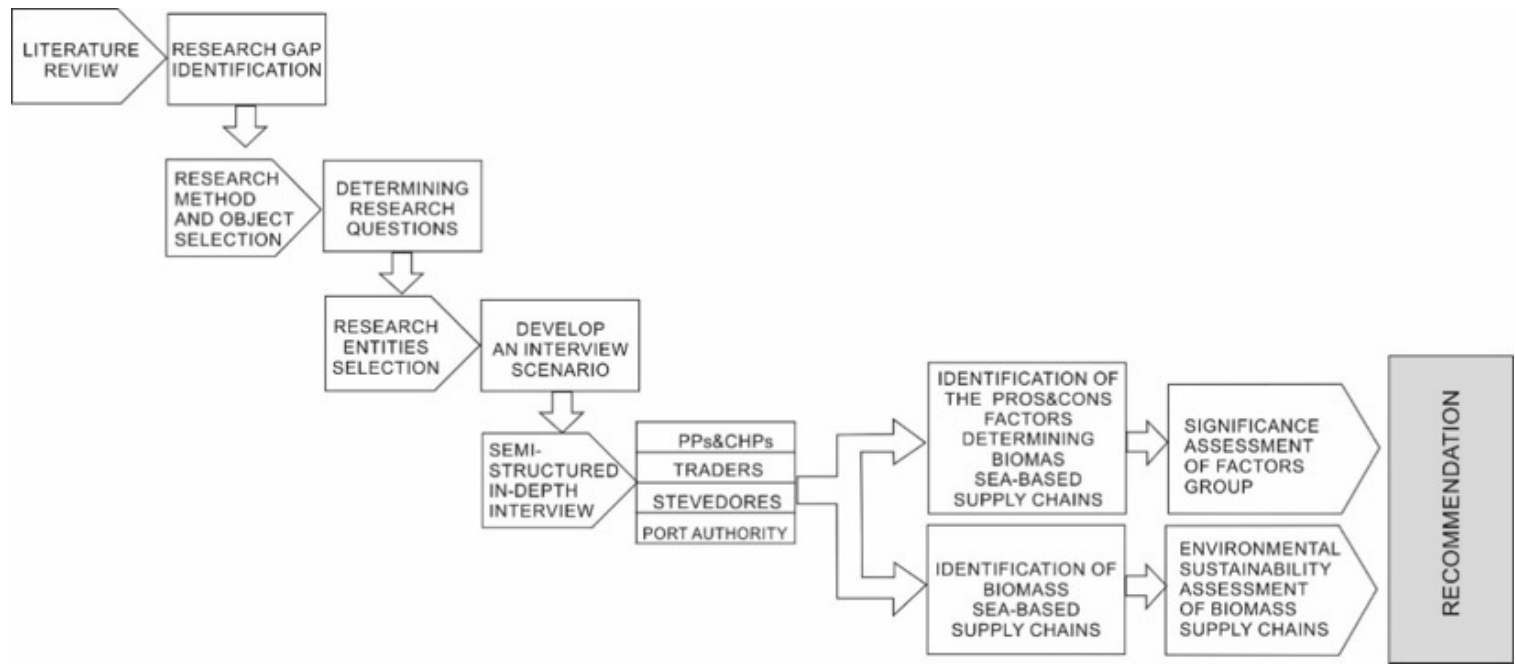

Figure 2. The main steps of the research process.

In the first stage, a literature review was carried out, which highlighted an existing research gap. In the second stage, the research method and main object of the research was selected. The object of the study was the port in Szczecin (Poland), which meets the criteria of a secondary port mainly due to its technical parameters and transshipment volumes [23]. The port in Szczecin is a universal port that can handle almost any kind of bulk cargo (e.g., coal, ores, grain, fuels, and other bulk cargoes) and general cargoes (including conventional general cargoes and containers). The port of Szczecin is located $70 \mathrm{~km}$ off the open sea, which determines its parameters. The port is currently able to serve vessels with a draught of up to $9.15 \mathrm{~m}$, however, the fairway is being dredged up to $12.5 \mathrm{~m}$ in depth and as soon as this project has been completed, the port will be able to handle vessels with a draught of up to $10.5 \mathrm{~m}$ (fully loaded vessels with a capacity of ca. $40 \mathrm{k}$ DWT). Similarly, as in the case of many seaports located in countries that are undergoing the process of energy industry decarbonization, the port in Szczecin has been suffering from the effects of the decrease in coal transshipment volumes (from 4.9 million tons in 1999 to 1.25 million tons in 2019 [40], which could be replaced by biomass. Unfortunately, this is not happening. Biomass transshipment volumes are subject to considerable fluctuations (Figure 3). 


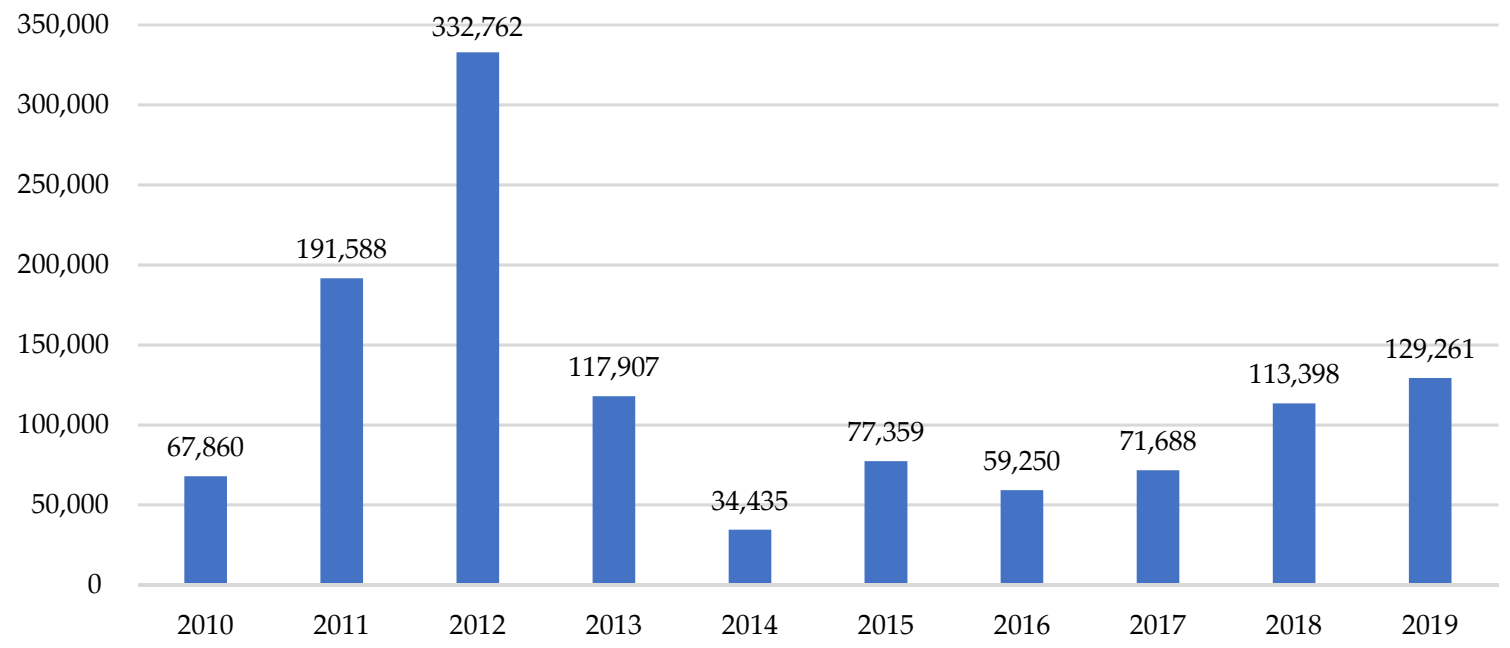

Figure 3. Cargo volumes of biomass in the port of Szczecin in 2010-2020 (tons).

The instability of biomass transshipment volumes in the port is determined by several factors. The main purpose of this research study was to identify and analyze these factors. The following research questions were formulated:

1. Which factors are pros and cons for the development of biomass sea-based supply chains from the perspective of various stakeholders?

2. How significant (low, medium, high, extreme) is the impact of the factors from the perspective of the stakeholders?

3. Which conditions should be met by a secondary port to become a node of a biomass sea-based supply chain?

In order to obtain answers to the posed research questions, the semi-structured indepth interview (IDI) technique was applied, which is perceived as the most appropriate data collection technique when open-ended questions are applied to elicit a depth of information from relatively few people [41].

According to Kvale [42], our IDI included the following stages of conducting indepth interviews: thematizing, designing, interviewing, transcribing, analyzing, verifying, and reporting.

The first step in conducting the semi-structured IDI was to identify entities engaged in biomass supply chains in Poland. The interviews were held with representatives of 12 selected entities connected with the biomass market, representing various nodes of the supply chain (Table 1).

Table 1. Characteristics of the interviewed entities.

\begin{tabular}{ccc}
\hline Type of Entity & Rationale for Selection (Role in the Supply Chain) & $\begin{array}{c}\text { No. of Interviewed } \\
\text { Entities }\end{array}$ \\
\hline $\begin{array}{c}\text { Power plants (PPs) and combined heat and } \\
\text { power plants (CHPs) }\end{array}$ & $\begin{array}{c}\text { Entities that have production plants in Poland (one of them has } \\
\text { production facilities in the port of Szczecin or its direct vicinity): } \\
\text { having at their disposal boilers dedicated for biomass combustion; } \\
\text { having experience in coal and biomass co-combustion } \\
\text { using various kinds of biomass (in combustion or co-combustion } \\
\text { processes) which is or was delivered via sea-land supply chains. }\end{array}$ \\
\hline Traders & $\begin{array}{c}\text { Cargo shippers, entities engaged in international trade and in } \\
\text { organization of biomass deliveries. }\end{array}$ \\
\hline Stevedoring companies (Stevedores) & Entities engaged in the Szczecin port operation, experienced in \\
biomass handling at the port.
\end{tabular}


The selection of the entities to be interviewed was dictated by their present and future role in biomass sea-land supply chains (Figure 4). The key role in this supply chain (in terms of coordinating both physical biomass flows as well as finance and information flows) is played by traders. Traders are also cargo shippers responsible for organizing the transport and logistic processes for their customers (PPs and CHPs). Stevedoring companies and the PA operate within a supply/demand model.

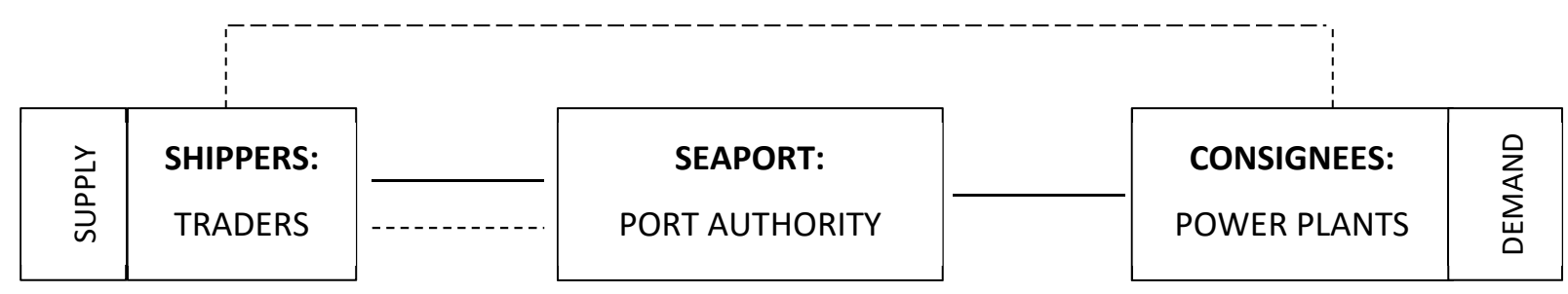

GOODS FLOWS (CARGO)

FINANCE AND INFORMATION FLOWS

(MANAGMENT OF CARRIAGE)

Figure 4. Relations between the examined stakeholders within the biomass sea-based supply chains.

The second step included preparation of the interview scenario, based on the knowledge gained from the current literature review, strategic (EU and national) documents, and market reports addressing, in particular, the issues of biomass sea-based supply chains in the context of decarbonization processes.

The third step focused on conducting the semi-structured IDIs (held by phone) in the period from September to November 2020. The conversations were supplemented with email correspondence held with the examined entities. First, the IDIs were carried out with the customers: PPs, CHPs, and suppliers: traders. Next, IDIs were conducted with the representatives of the PA and stevedoring companies. The examined entities were represented by persons in the capacity of Board President, Operations Director, Technical Director, Director for Business Development, Director for Import \& Export, Director for Environmental Protection, Main Specialist for Operations Control, Main Technologist, and Quay Manager. The survey applied open-ended questions so that respondents were able to expound on the topic and were free to answer the questions using their own words [41]. Due to the roles of the individual respondents in biomass supply chains, the questions addressed to them were diversified and were aimed at gathering subjective opinions held from the perspective of various stakeholders (Table 2).

The received responses were written down by the interviewer and documented in the form of interview notes. Then the received responses were analyzed, verified, and reported.

The obtained responses to the questions made it possible to identify the main factors affecting decisions made by the surveyed stakeholders in relation to biomass sea-based supply chains via secondary ports. The identified factors were first grouped (factor types) and categorized by the nature of their impact (PROS or CONS). To this end, the qualitative comparison decision-making technique was applied: Pros \& Cons Analysis [43]. The Pros $\&$ Cons Analysis made it possible to specify the nature of the impact of the identified factors: the pros (for) and cons (against) factors, while taking into account the various perspectives represented by the individual groups of the surveyed entities. The results obtained via the in-depth interviews were tabulated in the form of a pros and cons list supplemented with descriptions applying a narrative approach [44]. 
Table 2. Questions addressed to the responders during the semi-structured in-depth interviews.

\begin{tabular}{cl}
\hline Respondent & \multicolumn{1}{c}{ Question } \\
\hline \multirow{3}{*}{ PPs and CHPs } & Can biomass be a real alternative to coal as a resource to be used in the energy generation sector (in the transition \\
period and as the target solution)? & What benefits are associated with biomass use? \\
& Does (or should) the geographical location of production plants affect the choice of biomass sourcing countries? \\
& Which factors (positive and negative) will affect the future use of biomass as an energy source by the given entity? \\
\hline & What benefits are shown by overseas agro biomass compared to domestic agro biomass? \\
& Do the parameters of the sea access infrastructure in the port of Szczecin, the port infrastructure, and the quality \\
of the port services meet your expectations? & What is your assessment of the short- and long-term chances of development of overseas biomass supply via the \\
port in Szczecin? & What is the rationale for constructing a biomass terminal at the Szczecin port, which would offer transport and \\
& logistic services as well as (inward and outward) processing and industrial services? \\
\hline Stevedores & Can you name the most important features of biomass as a cargo, which affect its transport and logistic handling? \\
& Can you evaluate your capacities to effectively handle biomass (i.e., your transshipment and storage potential)? \\
& Can you assess the stability of demand for biomass transshipment and storage services? \\
& What measures may lead to increasing the role of biomass in the transshipment volume at the port of Szczecin in \\
the future? & What is your opinion on constructing a dedicated biomass terminal at the Szczecin port, which would offer \\
& transport and logistic services as well as (inward and outward) processing and industrial services? \\
& Could such a terminal become an element of a transformed service offer of the Szczecin port? \\
Do you plan any measures aimed at creating conditions for locating such terminals on the port premises (land \\
preparation plan, infrastructure development plan, utilities, etc.)?
\end{tabular}

Based on the Pros \& Cons analysis, a heat map was developed showing the importance of individual factor types for the identified stakeholders. For this purpose, in the first stage, the absolute frequency matrix $(A)$ was developed, which takes into account the total number of pros and cons factors in individual factor types (Appendix A):

$$
A=\left[a_{i j}\right]_{m \times n}
$$

where:

$m=5$ denotes for the number of factor types;

$n=4$ denotes for the number of analyzed types of entities;

$a_{i j}=$ denotes the number that is the sum of the identified pros and cons factors for individual factor types and types of entities.

In the next step, the relative frequency matrix (B) of the occurrence of $a_{i j}$ in the column $j$ was developed according to the formula:

$$
\sum_{i=1}^{m} a_{i j}=100 \%
$$

This relationship reflects the importance of the individual factor types for the identified types of entities (Appendix B).

On this basis, a heat map was developed, as per the following scale: low $(L)$, medium $(M)$, high $(H)$, extreme $(E)$. It was assumed that the value of $M$ represents the most evenly distributed factor frequency $(20 \%$, for $m=5)$ with a 3 percentage point error limit. Values below and above $M$ were defined as low $(\mathrm{L})$ and high $(\mathrm{H})$. Additionally, the extreme value $(E)$, which exceeds the mean value $(M)$ by $50 \%$ was determined. The individual ranges of values are as follows:

$$
\begin{gathered}
L=\langle 0 \% ; 17 \%) \\
M=\langle 17 \% ; 24 \%) \\
H=\langle 24 \% ; 30 \%) \\
E=\langle 30 \% ; 100 \%\rangle
\end{gathered}
$$

The interviews with traders also made it possible to identify potential biomass seabased supply chains that may be created via the port of Szczecin. Their identification also 
enabled attainment of the secondary research goal (i.e., assessment of the environmental sustainability of biomass sea-based supply chains via secondary ports). According to [11,12], one of the prerequisites for biomass export/import should be a carbon footprint analysis. Emissions from the entire biomass supply chains should lead to substantial reductions in comparison to the fossil-fuel equivalence. To verify this condition for the analyzed case study of the secondary port in Szczecin, the carbon footprint was estimated for the identified biomass sea-land versus land supply chains.

The analysis was carried out for four variants: two kinds of ships in maritime transport, one rail, and one road transport. Two types of vessels were taken into account to determine the carbon footprint of biomass supplies to the port of Szczecin by sea: handymax (fully loaded) and panamax (loaded up to the draft of $10.5 \mathrm{~m}$ ), which will be able to be served in the port after the fairway dredging project is completed in 2022. The parameters of the ships are presented in Table 3.

Table 3. Ship parameters taken into account in the carbon footprint calculation.

\begin{tabular}{ccc}
\hline Type of Ship & Panamax & Handymax \\
\hline GT & 43,506 & 25,278 \\
Deadweight (tons) & 79,649 & 39,072 \\
Draft (m) & 16.0 & 10.5 \\
Deadweight for draft of 10.5 m & 51,066 & 39,072 \\
Grain cargo capacity (m3) & 97,000 & 51,288 \\
Service speed (kn) & 14 & 14 \\
Fuel consumption in service speed (tons/day) & 39 & 18 \\
\hline
\end{tabular}

Source: Sea-web Ship [accessed on 8 January 2021].

The carbon footprint analysis of selected routes included the following research stages (Appendix C):

1. Maritime transport:

- determination of the method of loading ships—full or down — estimated based on the bulk density of the cargo and the analyzed ship's parameters: deadweight and grain capacity, (constant and variable stores were assumed to constitute $5 \%$ of $\mathrm{dwt}$ );

- determination of fuel consumption on the analyzed sea routes calculated based on the daily fuel consumption of the ships at service speed (Sea-web Ship) and the voyage duration (Sea distances); and

- carbon trace estimation-the analysis assumed that $\mathrm{CO}_{2}$ emissions were $3.114 \mathrm{~g}$ per gram of maritime fuel oil according to a study by the International Maritime Organization, IMO [45].

2. Road transport:

- determination of fuel consumption on the analyzed road routes-calculated based on the daily fuel consumption of an articulated vehicle (tractor with a semi-trailer) with an average fuel consumption of $36 \mathrm{~L} / 100 \mathrm{~km} \mathrm{[46];} \mathrm{and}$

- carbon trace estimation-the analysis assumed that $\mathrm{CO}_{2}$ emissions from diesel fuel was $2.64 \mathrm{~kg} / \mathrm{L}$.

3. Rail transport:

The analysis assumed emissions of $22 \mathrm{~g} \mathrm{CO}_{2} / \mathrm{tkm}$ according to the research [47], which takes into account:

- the average split between diesel and electric haulage;

- the average carbon intensity of the electrical power source;

- the average energy efficiency of the locomotive; and

- $\quad$ average train load factors.

The obtained research results made it possible to compare the carbon footprint being the outcome of the analyzed supply chains, which served as the basis for evaluating whether or not the proposed biomass sea-land supply chains meet the sustainability requirements (i.e., will lead to reduction in $\mathrm{CO}_{2}$ emissions compared to alternative land supply chains). 
In the last stage of the research, we verified the obtained results by matching the current theory with our empirical observations and presented the outcome in the discussion. The research results made it possible to provide the surveyed stakeholders with managerial implications.

\section{Results of the Study}

\subsection{Background of the Study: Biomass in the Assumptions of the Energy Policy for Poland 2040}

Following the provisions of the Energy Policy for Poland 2040 (EPP 2040), [48], the transformation of the existing electric power and heat generation system in Poland will be based on decreasing the reliance on coal. EPP 2040 assumes a decrease in the share of coal from 75\% to $56 \%$ by 2030 , and in the case of high prices of $\mathrm{CO}_{2}$ emission allowances to $37.5 \%$, followed by a downward trend in the subsequent years. The decarbonization processes are to be supported by an increased share of energy produced from RESs such as wind and solar energy. However, RESs such as solar and wind energy are unable to ensure a stable level of energy generation throughout the year. Among the RES technologies, biomass may meet this requirement, as it can be used in electric power and heat production both as the only resource and as part of co-combustion (e.g., with coal or municipal waste). The EPP 2040 assumptions underline that the utilization of biomass in Poland for energy generation purposes will be rising. The legislator sees the greatest potential for biomass utilization in the transformation of the heat production industry. Some of the biomass resources may also be used by the electric power generation industry. The document stresses that biomass supply should use transport solutions with the least negative environmental and economic effects.

However, it should also be noted that despite the expected increase in demand for biomass, the EPP 2040 assumptions do not stipulate an increase in the supply of forest timber for energy generation purposes. Currently, ca. 4 million $\mathrm{m}^{3}$ of forest timber sourced by the General Directorate of the State Forests in Poland is used by the energy sector. Concerning purchases of this resource, the energy sector intensively competes with other industries, predominantly with the furniture manufacturing industry. In this context, the potential of agro biomass is brought into focus. The Polish law regarding RESs [49] specifies the minimum quantities of agriculture biomass to be used in energy production. In terms of supply volume, the only significant segment of agro biomass in Poland is (cereal) straw. Its potential is estimated at ca. 3 million tons per year [50]. From the point of view of the energy sector's demand, the resources obtainable in Poland are insufficient, which leads to the need to import (mainly waste biomass). Additionally, in the area of domestic agro biomass supplies, the energy sector competes with agricultural production, the agricultural and food industry, and the processing industry. The indicated determinants of the national policy have a significant impact on the development of biomass sea-based supply chains via Polish secondary ports. The possible implications were discussed during the interviews with the stakeholders.

\subsection{The Pros \& Cons Factors That Determine the Development of Biomass Sea-Based Supply Chains via Secondary Ports (Stakeholders' Perspectives)}

The research findings obtained as a result of IDIs held with the stakeholders, combined with the knowledge sourced from the literature review and the strategic documents (in particular EPP 2040) made it possible to identify five main factor groups that affect the development of biomass sea-based supply chains, in other words:

1. biomass policy (EU and national),

2. biomass properties,

3. biomass sourcing,

4. biomass mindset, and

5. biomass logistics and transport (port-related).

Within the five factor groups, using the Pros \& Cons list, we identified the factors that had a positive or negative impact on the decisions of various surveyed stakeholders. The results are presented in Table 4. 


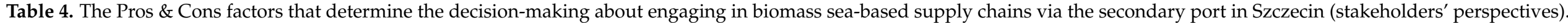

\begin{tabular}{|c|c|c|c|c|}
\hline Factor Types & PPs and CHPs & Traders & Stevedores & PA \\
\hline \multicolumn{5}{|c|}{ PROS $(+)$} \\
\hline $\begin{array}{l}\text { Biomass-related Policy } \\
\text { (EU and national) }\end{array}$ & $\begin{array}{ll}+ & \text { no costs of obtaining } \mathrm{CO}_{2} \text { emissions allowances } \\
+ & \text { need to introduce BAT conclusions for large } \\
& \text { combustion plants (LCP) } \\
+\quad & \text { possibility of obtaining funds from the EU Just } \\
& \text { Transition Mechanism (JTM) } \\
+ & \text { establishing the power market in Poland }\end{array}$ & $\begin{array}{ll}+ & \text { EU climate pressure forcing long-term supply } \\
\text { contracts (export and import) }\end{array}$ & $\begin{array}{l}\text { synergy of the EU transport, } \\
\text { energy and climate policy } \\
\text { (investments in superstructure) }\end{array}$ & $\begin{array}{l}+\quad \begin{array}{l}\text { synergy of the EU transport, energy and } \\
\text { climate policy (investments in infrastructure) }\end{array}\end{array}$ \\
\hline Biomass Properties & $\begin{array}{ll}+ & \text { zero-emission fuel }\left(\mathrm{CO}_{2}\right) \\
+ & \text { fuel that generates low emissions of } \mathrm{SO}_{2} \text { and } \mathrm{PM} \\
+ & \text { fuel that can be used in co-generation facilities } \\
+\quad & \text { fuel that can be used in fluidized bed boilers or } \\
& \text { can be co-combusted with coal } \\
+\quad & \begin{array}{l}\text { fuel characterized by the greatest production } \\
\text { stability among all RES }\end{array}\end{array}$ & 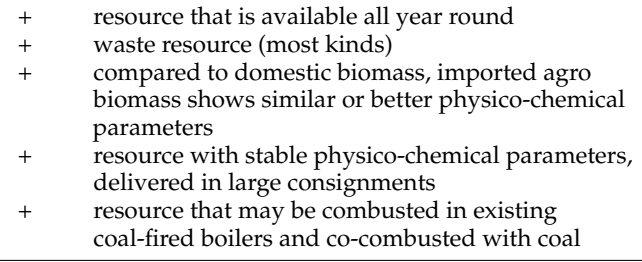 & $\begin{array}{l}\text { ability to cope with biologically } \\
\text { active cargo }\end{array}$ & \\
\hline Biomass Sourcing & $\begin{array}{l}+\quad \text { location of some of the production potential on } \\
\text { port premises/in direct vicinity of ports/in } \\
\text { cross-border area }\end{array}$ & $\begin{array}{l}+\quad \begin{array}{l}\text { shortage of domestic supply of the resource (agro } \\
\text { biomass) in the context of the planned increase in } \\
\text { demand }\end{array} \\
+\quad \text { a wide range of overseas biomass }\end{array}$ & 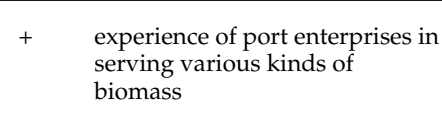 & \\
\hline Biomass Mindset & $\begin{array}{l}+\quad \text { high awareness (of some producers) of biomass } \\
\text { environmental sustainability }\end{array}$ & $\begin{array}{l}\text { high awareness of beneficial environmental effects } \\
\text { of using sea-borne transport in biomass supply }\end{array}$ & & $\begin{array}{l}+\quad \begin{array}{l}\text { alternative for the falling volumes of coal } \\
\text { transshipments }\end{array}\end{array}$ \\
\hline \multicolumn{5}{|c|}{ CONS (-) } \\
\hline $\begin{array}{l}\text { Biomass-related Policy } \\
\text { (EU and national) }\end{array}$ & $\begin{array}{ll}- & \text { unfavorable changes regarding the principles of } \\
\text { obtaining green certificates } \\
\text { limiting the financial support for investments in } \\
\text { facilities that apply co-combustion of biomass } \\
\text { and coal } \\
\text { possibility of applying (by some producers) for } \\
\text { extending the deadline for adapting to BAT } \\
\text { conclusions } \\
\text { acceptance of practices of (some) producers to } \\
\text { incur } \mathrm{CO}_{2} \text { emission fees and substitution fees } \\
\text { instead of wider use of RES }\end{array}$ & $\begin{array}{l}\text { weak pressure exerted by the national policy on } \\
\text { faster decarbonization of the energy sector in a } \\
\text { short-term perspective } \\
\text { recommendations found in the EU policies } \\
\text { showing preference for using local biomass } \\
\text { increased competitiveness of domestic forest } \\
\text { biomass as a result of changes in the regulations } \\
\text { on wood origin certificates }\end{array}$ & $\begin{array}{l}\text { - } \quad \text { no financial support for port } \\
\text { regions under the EU Just } \\
\text { Transition Mechanism }\end{array}$ & \\
\hline
\end{tabular}


Table 4. Cont.

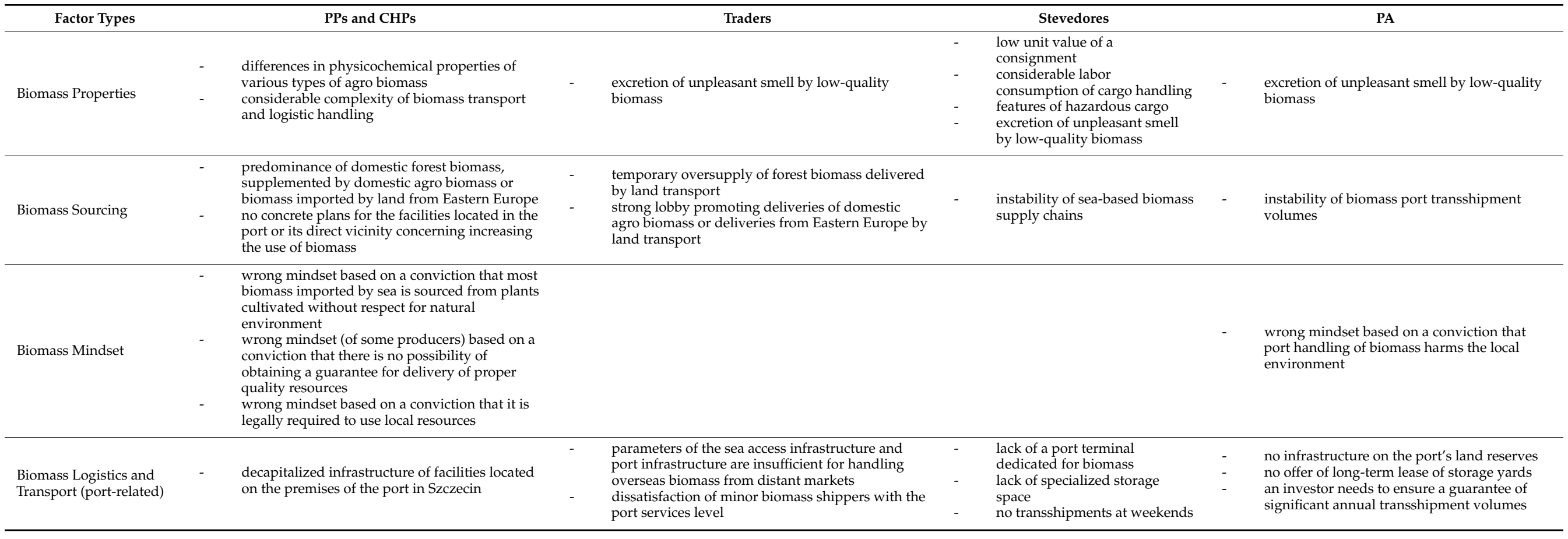


The research results indicate the differing significance of the identified factor groups (as per the number of factors in a given group) and the different nature of their impacts (pros or cons) from the perspective of various surveyed stakeholders. This is because these entities play different roles in overseas biomass supply chains. Referring to:

\section{Biomass-Related policy (EU and national)}

PPs and CHPs perspective: The pros factors for using biomass are connected with the costless obtaining of emissions allowances. Entities that invest in biomass power units will also be able to meet the best available technique (BAT) conclusions for large combustion plants (LCPs). BAT conclusions for LCPs introduce restrictive requirements regarding permissible quantities of pollutant emissions. The conclusions will be coming into force in August 2021. However, those entities can seek an extension of the adaptation period. This regards the entities that are required to make very costly investments. Extending the adaptation periods may delay the transformation of the energy sector. Simultaneously, the Polish regions affected by the effects of fading out of the coal mining industry will be the most important consumer under the EU Just Transition Mechanism. However, obtaining support is conditioned by preparing territorial plans for the just transition. The plans have to include the goal of achieving climate neutrality by 2050, which may be facilitated by increased use of biomass. Establishing a power market in Poland should be another incentive for the construction of new power units that use biomass. In return for readiness and commitment to supply specific amounts of electric power in periods of increased demand, the owner of such a power unit will receive remuneration under an extended (concerning standard) contract term. The cons factors for biomass use by the energy market participants, in turn, include termination (for many of them) of the 15-year support period for biomass and coal co-combustion as well as the change made in 2017 with regard to the regulations on green certificates (transition from a public aid system to an auction-based system). The transformation of the energy sector aimed at a wider use of RESs is also hindered by the fact that many large companies are inclined to pay the $\mathrm{CO}_{2}$ emission fees and substitution fees instead of implementing investments in, for example, biomass power units.

Traders' perspective: In their opinion, the pros factors include first and foremost the EU's climate pressure in connection with meeting the goal of climate neutrality by 2050 . This will have a positive effect on establishing long-term contracts for biomass supply, both to and from Poland. At the same time, traders underlined numerous cons factors such as a lack of pressure exerted by the national policy to accelerate the transformation of the energy sector. In their opinion, the EU recommendations do not facilitate the development of agro biomass sea-land supply chains. They encourage the use of local biomass. This affects the national policy. In a short-term perspective, this policy harms an increase in demand for agro biomass. The introduced regulations regarding certification of wood origin incline biomass shippers to make use of predominantly domestic forest biomass.

Stevedores' and the PAs' perspective: These entities see pros factors mainly in the form of intermediate benefits derived from the synergy of the transport policy with the EU energy and climate policies, connected with port investments financing (sustainable maritime transport). In their opinion, when the entrance fairway to the port and the quays has been dredged, cargo shippers (including biomass shippers) will view the port more favorably. In the case of the PA, this synergy will also make it possible to improve the parameters of the inland waterways that connect the port with the hinterland (pros factor). According to the stevedores, the cons factor is the lack of support under the EU Just Transition Mechanism for the port regions where coal transshipments have decreased significantly.

\section{Biomass Properties}

PPs and CHPs perspective: In their view, the pros factors include first and foremost the biomass properties and possibilities of applying it as a fuel in the energy sector; it is considered to be a zero-emission fuel in terms of $\mathrm{CO}_{2}$, a low emission fuel in terms 
of $\mathrm{SO}_{2}$, generating low emissions of $\mathrm{PM}$, which can be used in co-generation facilities or in fluidized bed boilers or can be co-combusted with coal. Furthermore, this fuel is characterized by the greatest production stability among all RESs. Among the cons factors, some of the surveyed entities identified the high complexity of transport and logistic handling of biomass. Some producers were also discouraged by negative experiences connected with the combustion of agro biomass that was mischosen in light of the technical facilities (boilers) that they had been using.

Traders' perspective: Among the pros factors, these entities enumerated the advantages of biomass transported via sea-land supply chains compared to domestic biomass: all-year availability of the resource, the fact that most kinds of biomass are waste materials, similar or better physicochemical properties, the stability of the parameters, and the possibility of being co-combusted with coal, and in the future (after coal has been eliminated), the possibility of being combusted on its own in the still functioning coal-fired boilers. The same group of stakeholders also pointed to the negative consequences (cons factors) of the irresponsible actions of some biomass shippers. These are with regard to the deliveries of low-quality biomass (negative impact on the local environment), which has a detrimental effect on the resource image perceived by customers.

Stevedores' and PA's perspective: In terms of pros factors, these respondents pointed to their experience in biologically active cargo handling (competitive advantage). The cons factors identified by stevedores are in turn related to biomass features that are decisive in terms of cargo handling at ports: considerable labor consumption and low unit value (no possibility of increasing the profits from providing additional services). The entities also indicated the significance of other undesired phenomena connected with biomass handling at ports: odor excretion, risk of self-ignition, and dusting. Undesired phenomena affecting the relations with the direct environment of a seaport and publicized by mass media were also noticed by the port authority in the context of a negative impact on the port's public image (a cons factor). Similarly, as traders, the PA pointed to the low quality of biomass as the reason for this problem.

\section{Biomass Sourcing}

PPs and CHPs perspective: Currently, most biomass combustion facilities in Poland predominantly use domestic forest biomass supplemented with agro biomass coming from Poland or Eastern Europe. However, according to these entities, the pros factor for overseas biomass is the geographical location of production facilities. Overseas biomass deliveries may be wanted by facilities located on port premises or in the direct vicinity of seaports. Still, the facilities located in the neighborhood of the port in Szczecin (the Polish hinterland) do not have any concrete plans about the increased use of biomass in the future (cons factor).

Traders' perspective: A cons factor is the shortage of domestic agro biomass supply in the context of the expected increase in demand for this resource by the energy sector. The existing significant supply of agro biomass pertains only to cereal straw; however, it is not sufficient. A solution to the problem of biomass shortage may be the broad offer of overseas biomass (of different kinds, processing level, sourcing countries). At the same time, traders expressed their pessimistic view on short-term perspectives of increased export and import of overseas biomass (cons factor). This can be attributed to the slow changes in the energy sector, the temporary oversupply of forest biomass (as a result of the drought) and warm winters (climate changes). These entities, at the same time, stressed that the delivery terms on the market were dictated by the parties on the demand side (PPs and CHPs). In case of low demand, deliveries of the resources are dominated by domestic biomass carried by road transport. In their view, sea-based supply is hindered by a strong lobby that promotes the supply of domestic biomass or biomass imported from Eastern Europe.

Stevedores' and the PAs' perspectives: According to the stevedores, the major pros factor is first and foremost their experience in the port handling of different kinds of biomass, both exported (mainly to the Scandinavian markets-grain terminal in the port of Szczecin) and imported (wood biomass from the Baltic States, exotic biomass from 
Southern Europe, Africa, and Asia-the solid fuel terminal in the port of Szczecin). In the context of pros factors, the Port Authority sees biomass as one of the alternatives for the decreasing volumes of coal transshipment. However, the entities identified the instability of biomass sea-land transport chains as the key cons factor. Unexpected changes in the resource origin and destination points discourage the stevedores from investing in a superstructure dedicated for this cargo group. Another cons factor indicated by the PA concerning investing in the infrastructure is the considerable variability of annual biomass transshipments in the volume of the Szczecin port operations (over the last decade).

\section{Biomass Mindset}

Power plants' and CHPs' perspective:

The pros factor is the high awareness of some entities of biomass environmental sustainability. This is reflected in the actual investment measures taken by them (the goals of decarbonization of the energy sector). The plans to reach zero-emission by one of the surveyed entities exceeded the perspectives planned by the EU by as many as 20 years. At the same time, some of the entities demonstrated the misplaced knowledge that most biomass imported by sea is obtained from plants cultivated without respect for natural ecosystems, which is difficult to guarantee supplies of good quality resources, and that the law requires making use of local biomass (cons factors).

Traders' perspective: A pros factor is the considerable knowledge held by these entities about overseas biomass and the high awareness of environmental benefits resulting from using sea-borne transport in biomass deliveries versus land chains (circular economy). In their opinion, an analysis of the carbon footprint should be the main criterion when choosing the sourcing country and the kind of transport for biomass supplies.

PA's perspectives: The pros factor is the awareness that biomass may become an alternative for the fading transshipments of coal. However, the cons factor is the misplaced knowledge about a negative impact of biomass port handling on the local environment (odor excretion, impact on the port's image). This phenomenon pertains only to handling low-quality biomass.

5. Biomass Logistics and Transport (port-related)

PPs' and CHPs' perspective: The pros factor is the possibility of making direct deliveries of overseas biomass to the plants located in the port, or of intermediate deliveries made via inland waterway transport to plants located in the close hinterland of the port. However, the infrastructure of the facilities located on the port premises and in the close hinterland is decapitalized (cons factor). Nevertheless, PPs located in the vicinity of Berlin (i.e., the close hinterland of the port of Szczecin) have access to the inland waterway ports and prefer deliveries by barge (pros factor).

Traders' perspective: The pros factor for biomass export is the sufficient parameters of the sea access infrastructure and the port infrastructure found in the port of Szczecin. However, traders held a different opinion about these technical parameters when it came to biomass import, particularly from the distant hinterland (cons factor). These entities thought that the competitiveness of the port in Szczecin would improve after the fairway and the quay basins have been dredged to the depth of $12.5 \mathrm{~m}$. It should also be noted that these entities showed different opinions about the quality and time of port services, depending on the scale of their business activity (large or small cargo shippers). The larger cargo shippers (shipping several dozen tons of cargoes per year) were satisfied with the quality and time of port services (a pros factor), as opposed to the smaller shippers (a few thousand tons of cargoes per year), which is a cons factor. The latter group indicated, inter alia, that transshipment took too much time, that the service providers were not flexible in engaging the un/loading equipment, there was a lack of specialized storage space and a lack of possibility of a long-term lease of storage yards. All the cargo shippers agreed that a dedicated terminal for biomass handling would make the port of Szczecin more attractive for this type of cargo. In their opinion, a biomass terminal should be provided with an appropriate storage potential: storage yards and warehousing facilities of a $20-30 \mathrm{k}$ ton 
capacity each, and with a rail infrastructure to enable handling two whole trains at the same time.

Stevedores' perspective: A pros factor is first and foremost the possibility of using the universal port equipment for biomass handling. One of the surveyed entities noticed an additional asset: the state-of-the-art fire safety system in place. However, none of the surveyed entities had at its disposal a port terminal dedicated for biomass, featuring specialized storage space (cons factor). Another problem is that there is no possibility of providing port services at weekends.

PAs' perspective: The managing entity underlined its openness to creating conditions for the development of dedicated transshipment and storage terminals (pros factor) including a biomass terminal, and for related (inward and outward) processing and industrial services (provisions in strategic documents of the PA). Nevertheless, currently (i.e., in the year 2020), the PA does not have available areas provided with infrastructure that could be used as storage yards for long-term lease (cons factor). Moreover, a condition that is difficult to meet by any entities interested in investments on the port premises is the need to guarantee significant transshipment volumes per year.

4.3. The Verification of the Environmental Sustainability of the Biomass Sea-Based Supply Chains via the Secondary Port in Szczecin: The Results of the Carbon Footprint Analysis

The surveyed traders group had considerable experience in organizing sea-based supply chains of various kinds of biomass between various markets, also in the hinterland of the port in Szczecin. The recommendations provided by these entities constituted the basis for distinguishing four biomass sea-based supply chains, which were later evaluated in terms of environmental sustainability. The carbon footprint analysis was carried out for four consignments over four routes:

1. Palm Kernel Shell (PKS): on the Sandakan (Malesia)-Szczecin route.

2. Olive pomace: on the Bilbao (Spain)-Szczecin route.

3. Sunflower husk pellet: on the Mariupol (Ukraine)-Szczecin route.

4. Willow chips: on the Riga (Latvia)-Szczecin route.

Studies have shown that the supply of willow chips on the Riga-Szczecin route generates the lowest $\mathrm{CO}_{2}$ emissions per ton of cargo (Table 5). This is due to low specific emissions from ships and a much shorter sea route compared to the land route (30\% shorter than road route and $15 \%$ shorter than the rail route). $\mathrm{CO}_{2}$ emissions are nearly twice as high in the case of olive pomace deliveries performed by a handymax ship, and three times as high if the delivery was performed by a panamax vessel. The highest $\mathrm{CO}_{2}$ emissions of maritime deliveries were in the case of PKS delivered from South-East Asia. This is mainly due to the much greater distance to Poland than in the other instances. In the case of PKS, $\mathrm{CO}_{2}$ emissions from maritime deliveries exceeded $\mathrm{CO}_{2}$ emissions from the other analyzed rail routes, and-in the case of willow chips-even the road routes.

Table 5. $\mathrm{CO}_{2}$ emissions per ton of biomass in the analyzed transport chains.

\begin{tabular}{ccccc}
\hline Means of Transport & $\begin{array}{c}\text { Palm Kernel Shell: } \\
\text { Sandakan-Szczecin } \\
\text { Route }\end{array}$ & $\begin{array}{c}\text { Olive Pomace: } \\
\text { Bilbao-Szczecin } \\
\text { Route }\end{array}$ & $\begin{array}{c}\text { Sunflower Husk } \\
\text { Pellets: } \\
\text { Mariupol-Szczecin } \\
\text { Route }\end{array}$ & $\begin{array}{c}\text { Willow Chips: } \\
\text { Riga-Szczecin Route }\end{array}$ \\
\hline Handymax ship & 59.4 & 6.7 & 24.1 & 3.9 \\
Panamax ship & 74.8 & 11.0 & 33.0 & 4.4 \\
Truck & - & 80.6 & 79.8 & 47.5 \\
Train & - & 48.2 & 51.4 & 22.1 \\
\hline
\end{tabular}

It is also interesting that in most cases, sea transport by a panamax vessel generates a higher carbon footprint than transport by a handymax one. This is the effect of a lower cargo volume resulting from the reduced draft of ships entering the port of Szczecin (after deepening the fairway, it will be only $10.5 \mathrm{~m}$ ). In the case of PKS, olive pomace and 
sunflower husk pellets deliveries, a single loading batch on a panamax ship may be only $30-70 \%$ greater than in the case of a handymax one, while fuel consumption is twice as high. This dependence does not apply to the transport of willow chips, for which the $\mathrm{CO}_{2}$ emissions generated by panamax and handymax vessels are very similar. This is due to the low bulk density of this cargo, which means that in both cases, the ships are fully loaded.

Much smaller differences in $\mathrm{CO}_{2}$ emissions occur when the calorific value of individual types of biomass is taken into account (Figure 5).

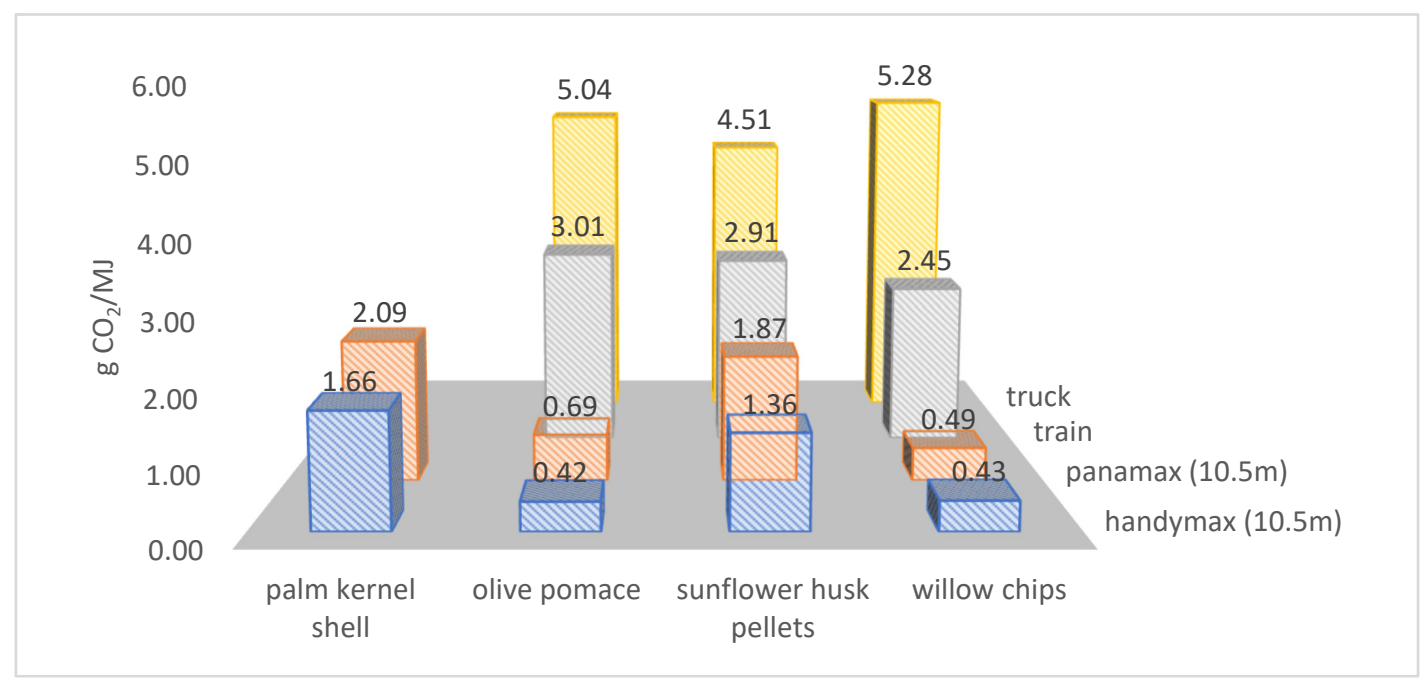

Figure 5. $\mathrm{CO}_{2}$ emissions per calorific value of biomass in the analyzed transport chains.

The least calorific value is shown by willow chips (almost twice as small as in the case of the other kinds of biomass). This difference means that olive pomace deliveries from Spain by a handymax ship generated a similar carbon footprint as deliveries of willow chips from the Baltic states. Interestingly, sea-borne carriage of sunflower husk pellets is much more beneficial in terms of emissions than rail deliveries, even though the sea distance is more than three times longer than the rail route. It is worth noting that currently, these pellets are delivered to Polish power plants mainly by rail. Invariably, PKS transport from Asia to Poland poses a significant burden to the environment.

The completed analysis has shown that biomass deliveries made via sea-borne transport to the power plants located in the direct vicinity of the port in Szczecin will be more advantageous in terms of GHG emissions compared to other means of transport. This is with regard to all the analyzed routes. Interestingly, even deliveries made from very distant markets (PKS from Malaysia) generate a lower carbon footprint than any other analyzed land supply chain. Therefore, the construction of a biomass terminal may contribute to establishing biomass sea-based supply chains, thus fitting into the idea of a sustainable development of transport.

Moreover, despite the relatively low bulk density of biomass, sea-based deliveries made employing not fully loaded panamax bulk carriers will generate greater external effects compared to using a fully loaded handymax vessel. It is an advantageous situation, as after the fairway has been dredged to the depth of $12.5 \mathrm{~m}$, handymax vessels will be free to enter the port in Szczecin, as opposed to panamax vessels.

\section{Discussion}

Our research study made it possible to identify five groups of factors that affect the functioning and development perspectives for biomass sea-based supply chains via secondary ports: (1) Biomass-related policy (EU and national), (2) Biomass properties, (3) Biomass sourcing, (4) Biomass mindset, and (5) Biomass logistics and transport (portrelated). In this respect, our research confirms and extends the conclusions made hitherto concerning the pros and cons factors that determine the biomass supply chains. At the 
same time, our research study made it possible to determine and specify the relevance of the factor groups for decisions made by various stakeholders of sea-based and secondary port-related biomass supply chains. We used the heat maps to visualize the research results (Figure 6). The study demonstrated in particular that the relevance of the particular factor groups differed depending on the role played by such entities in the overseas biomass supply chains.

\begin{tabular}{|c|c|c|c|c|}
\hline Factor types & $\begin{array}{c}\text { PPs and } \\
\text { CHPs }\end{array}$ & Traders & Stevedores & PA \\
\hline Biomass-related Policy (EU and national) & E & M & L & L \\
\hline Biomass Properties & H & E & E & L \\
\hline Biomass Sourcing & L & M & L & L \\
\hline Biomass Mindset & L & L & L & M \\
\hline Biomass Logistics and Transport (port-related) & L & M & E & E \\
\hline
\end{tabular}

Figure 6. Evaluation of the relevance of the identified factor groups for decisions made by stakeholders of biomass sea-based supply chains.

In general, decisions made by PPs and CHPs (representing the demand) were to the greatest degree affected by the factors connected with the biomass-related policy and biomass properties, determining the processes of the energy sector transformation toward decarbonization. For traders (representing the supply), the most important factors are those connected with biomass properties. At the same time, due to the coordinating role of these entities in biomass supply chains, other identified factors were also of significance, especially those related to biomass sourcing, biomass logistics and transport as well as biomass-related policy. For stevedores and the PA, operating within a supply-demand model, the factors of key importance are of course those of biomass logistics and transport (port-related). Moreover, the stevedores' decisions were significantly affected by factors from the biomass properties group, which determine the physical handling of biomass in the port. For the PA, in turn, considerable weight was attached to factors from the biomass mindset group as the PA's task, besides the landlord function, is promotional activity within the corporate social responsibility (CSR) framework. Our research study also found that the identified factor groups had both positive (pros) and negative (cons) impacts on decisions made by the surveyed entities. The impact of any particular factor group was also different from the perspective of the individual stakeholders.

Biomass-related policy (EU and national) in a long perspective favors PPs and CHPs that take measures connected with transformation of the production potential (decarbonization). It is also advantageous for the traders interested in developing operations connected with biomass trading and transport handling. Taking into account also the synergy of biomass-related policy with the objectives of the transport policy, it is indirectly favorable to entities interested in increasing the port transshipment volumes of this resource (stevedores, PA). Nevertheless, the national regulations based on the EU policies are more favorable for biomass derived locally, which is a cons factor for overseas supply development. The current policy also allows for a temporary extension of the transformation process (decarbonization) of production plants still using traditional sources of energy. Moreover, in terms of mechanisms supporting the process of energy sector transformation, the policy ignores the port regions affected by a drop in coal transshipment volumes. This excludes the port-related entities (stevedores and PA), for example, from financial support programs.

Biomass properties provide a wide range of possibilities of being used by PPs and CHPs in co-generation facilities or in fluidized bed boilers or they can be co-combusted with coal. In connection with low emissions (cost savings) and high stability of production process, in comparison with other RESs, to the largest extent, these factors determine decisions made by PPs, CHPs as well as traders. Additionally, other factors important for 
traders include economic and environmental advantages of biomass transported in seabased supply chains over domestic biomass/biomass delivered via land supply chains (allyear-round availability, waste status, benefits resulting from large consignment deliveries via seaports). Moreover, PPs, CHPs, and stevedores indicate the complexity of biomass handling at the port as a significant factor of developing biomass sea-based supply chains. However, as opposed to stevedores in secondary ports, for PPs and CHPs, this is a cons factor, as from their perspective, this constitutes a competitive advantage (capability to handle diversified groups of cargoes). Simultaneously, a particularly unappealing factor for stevedores is the low unit value of biomass consignments. The PA also identified the risk of a negative impact of biomass handling at the port on the social environment of the port, which may deteriorate its image.

Biomass sourcing within sea-based supply chains is economically attractive for PPs and CHPs located on the port premises or its vicinity. From the traders' perspective, in the long run, overseas sourcing has an advantage due to the limited supply of domestic agro mass. However, traders negatively assessed the short-term forecasts for overseas sourcing of biomass, predominantly due to the slow process of decarbonization and the competition from domestic forest biomass and agro biomass delivered by land. These factors have a considerably destabilizing effect on sea-based biomass supply chains. This is reflected in the operations of stevedores, who despite a considerable experience in overseas biomass handling (import, export), pointed to the instability of annual transshipment volumes as a factor that has a significant discouraging effect on investing in any biomass dedicated superstructure. Instability of port transshipment volumes also had a negative impact on the PA's perception of biomass as an alternative cargo to replace the decreasing volumes of coal transshipments.

Biomass mindset, in its positive sense, is specified by a high awareness of economic and environmental benefits resulting from the utilization of biomass, demonstrated by some of the PPs and CHPs and all traders. In the case of some PPs and CHPs, this is reflected in the investment measures related to the process of the energy sector decarbonization. Among all the surveyed entities, traders demonstrated the highest level of awareness of the environmental benefits resulting from utilization of overseas biomass delivered via sea-based supply chains compared to land supply chains. At the same time, it is possible to observe "a wrong biomass mindset" among some of the surveyed PPs and CHPs. Its source may be misplaced knowledge about biomass as well as negative experiences related to the combustion of inappropriate kinds of and/or bad-quality biomass. These factors also led to developing a mistaken view by the PA that development of activities related to transport and logistic handling of biomass would harm the port's image.

Biomass (port-related) logistics and transport cover the factors connected with the technical equipment of the port, its access from the sea and land as well as the quality and lead time of the transport and logistic services. In this context, the pros factor for engagement of PPs and CPHs in biomass sea-based supply chains is an appropriate quay infrastructure enabling direct handling of maritime and/or barge deliveries (in facilities located in the port or its direct vicinity). At the same time, traders pointed out that the parameters of the port infrastructure and the sea access infrastructure, which were observed in secondary ports, were sufficient for biomass export, but not satisfactory for all importers. There were also different opinions regarding the quality and lead time of port services, which significantly affected the decisions made by traders. The ones satisfied with the quality and lead time of services provided in the port were the traders generating large annual volumes of biomass, as opposed to the traders shipping only small consignments. However, stevedores believed that the universal port superstructure that was in place sufficed for the proper handling of the current biomass volumes. Furthermore, all traders agreed that a terminal dedicated for biomass handling would make the offer of the secondary port more attractive. From the point of view of the PA, the factor in favor of establishing a biomass terminal was also the availability of land reserves in the port and access to inland waterways, which may play a vital role in handling biomass in the close 
hinterland. Still, it would be necessary to provide undeveloped areas with the necessary infrastructure, which according to the PA would be possible if specific annual volumes of biomass transshipments were guaranteed.

Our research study also showed that traders had the highest awareness (among the surveyed stakeholders) of the environmental benefits connected with the development of biomass sea-based supply chains. They associated utilization of biomass with the idea of a circular economy and they proposed that the carbon footprint should be the indicator to verify the biomass supply chains. This stance can also be found in other studies completed thus far, which considered the carbon footprint as one of the criteria of assessing sustainable sourcing of overseas biomass (e.g., $[11,15,18])$. The carbon footprint analysis performed in this study showed that biomass sea-based supply chains generated lower $\mathrm{CO}_{2}$ emissions than alternative land deliveries.

\section{Conclusions}

Our research study showed that (1) overseas agro biomass (wastes and residues) may become a significant tool in the process of the decarbonization of economies that are heavily reliant on coal as a transition fuel and as a stable RES in the structure of the future energy mix; and (2) biomass sea-based supply chains may be an attractive alternative for secondary ports affected by negative outcomes of decarbonization (fading coal transshipments volumes). However, our research has shown that the development of biomass sea-based supply chains is predicated on numerous factors. The research study described in this paper made it possible to identify and assess the significance of the pros and cons factors for establishing biomass sea-based supply chains through secondary ports in the context of decarbonization processes and from the perspective of major stakeholders, in other words: (1) Biomass-related policy (EU and national), (2) Biomass properties, (3) Biomass sourcing, (4) Biomass mindset, and (5) Biomass logistics and transport (port-related).

The research study showed that the current EU policy concerning the energy mix had a direct and indirect stimulating effect on long-term perspectives for the development of biomass sea-based supply chains via secondary ports. Due to biomass properties, there are various possibilities of combustion of this resource. Given the conditions related to biomass sourcing and port-related biomass logistics and transport, secondary ports may become elements of sustainable (attractive in economic and environmental terms) biomass supply chains.

Moreover, biomass may not only become an alternative cargo in secondary ports to replace the fading coal transshipments, but also stimulate the development of other service and production operations on the port premises. However, this would require overcoming several cons factors, which destabilize or hinder the development of sea-land supply chains via secondary ports such as slow decarbonization, misplaced knowledge about biomass, failing to account for the carbon footprint when choosing biomass sources, insufficient quality, and too long lead times of biomass handling services in the port (in the case of small consignment shippers), biomass low value and properties that make it less attractive as a port cargo, limited parameters of the sea access infrastructure, and of the port infrastructure in terms of economic profitability of biomass import.

A solution to the latter problems is a dedicated biomass terminal. Provided that it is located well away from housing estates and that traders make sure only high-quality biomass is delivered, any unfavorable environmental impact may be significantly mitigated. Along with upgraded parameters of sea access infrastructure and improved port facilities, a dedicated biomass terminal may contribute to the increased economic and environmental efficiency of sea-land transport chains (smaller carbon footprint). Together with an appropriate superstructure, a biomass terminal may provide sufficient port service efficiency and enable harmonization of deliveries. Establishing a dedicated biomass terminal does not mean that this type of cargo can no longer be handled at the already existing (universal or specialized) terminals. 
First, the implementation of the proposed solutions requires political actions aimed at the elimination of the indicated cons factors. The policy then influences the decision making of individual stakeholders of biomass sea-based supply chains in the sequence: (1) PPs and CHPs, (2) Traders, (3) Stevedores, and (4) Port Authority. Given the above, the following major recommendations were formulated for the individual stakeholders of sea-based supply chains:

1. PPs and CHPs should change the criteria for selecting biomass supply markets. The evaluation should be made in the context of the lowest environmental costs connected with the transport. These entities should also verify and supplement their knowledge about biomass imported by sea, particularly taking into account the waste nature of overseas agro biomass.

2. Traders should guarantee deliveries of high-quality resources that will not pose problems to stevedores and the PA in terms of relations with the local environment and that will not harm the overall opinion about biomass as a cargo group.

3. Stevedores should provide high quality and appropriate lead times of port services to various biomass shippers (regardless of the annual transshipment volumes that they generate) at the functioning port terminals. A dedicated biomass terminal will also need an operator (physical handling of transshipments).

4. The PA should provide technical conditions (in addition to the declarations contained in the strategic documents) for establishing a dedicated biomass terminal (providing utility service connections, connections with the external infrastructure) and serving larger vessels. It is also necessary to change the criteria for the evaluation of any potential port investors (creating conditions for investment by minor shippers). In the future, the PA should also increase its engagement in integrating the sea-based biomass supply chains, which has also been pointed out in other studies [37].

The case study method applied in the study made it possible to understand the complex area of factors determining the creation of biomass sea-based supply chains in Poland. However, the adopted methodology has its constraints. The findings obtained as a result of the study may not be fully generalized (statistical generalization). Nevertheless, the findings may be partly generalized with the meaning of analytic generalization [38]. The research findings may be useful to other stakeholders of biomass supply chains interested in the development of sea-based deliveries, in particular, for stevedoring companies and port authorities of other secondary ports that have similar potential and face similar challenges to help them elaborate their strategies for engagement in biomass supply chains.

Author Contributions: Conceptualization, M.M.; Data curation, M.P.; M.M., and I.K.; Formal analysis, M.M.; Investigation, I.K., M.M., and M.P.; Methodology, I.K. and M.M.; Resources, M.M.; Writing—original draft, M.M., M.P., and I.K.; Review and editing, M.M., M.P., and I.K. All authors have read and agreed to the published version of the manuscript.

Funding: The project was financed within the framework of the program of the Minister of Science and Higher Education under the name "Regional Excellence Initiative" in the years 2019-2022; project number 001/RID/2018/19. The amount of financing: PLN 10,684,000.00.

Institutional Review Board Statement: Not applicable.

Informed Consent Statement: Not applicable.

Data Availability Statement: Not applicable.

Acknowledgments: We would like to thank all the reviewers and the journal editors for their insightful comments and suggestions toward improving our manuscript.

Conflicts of Interest: The authors declare no conflict of interest. 
Appendix A. Absolute Frequency Matrix

$$
A=\left[\begin{array}{llll}
8 & 4 & 2 & 1 \\
7 & 6 & 5 & 1 \\
3 & 4 & 2 & 1 \\
4 & 1 & 0 & 2 \\
3 & 4 & 5 & 6
\end{array}\right]
$$

\section{Appendix B. Relative Frequency Matrix}

$$
A=\left[\begin{array}{cccc}
32 \% & 21 \% & 14 \% & 9 \% \\
28 \% & 32 \% & 36 \% & 9 \% \\
12 \% & 21 \% & 14 \% & 9 \% \\
16 \% & 5 \% & 0 \% & 18 \% \\
12 \% & 21 \% & 36 \% & 55 \%
\end{array}\right]
$$

Appendix C. Parameters and Partial Results of the Research on CO2 Emissions in the Investigated Biomass Transport Chains

\begin{tabular}{|c|c|c|c|c|}
\hline Characteristics & Palm Kernel Shell & Olive Pomace & Sunflower Husk Pellets & Willow Chips \\
\hline Calorific value $(\mathrm{GJ} / \mathrm{t})$ & 15.8 & 16 & 17.7 & 9 \\
\hline Bulk Density $\left(\mathrm{kg} / \mathrm{m}^{3}\right)$ & 550 & 780 & 600 & 400 \\
\hline \multicolumn{5}{|c|}{ sea transport } \\
\hline Sea route & Abidjan-Szczecin & Bilbao-Szczecin & Mariupol-Szczecin & Riga-Szczecin \\
\hline Sea distance $(\mathrm{Nm})$ & 4440 & 1481 & 4431 & 476 \\
\hline Voyage time in $14 \mathrm{kn}$ speed (days) & 13.2 & 4.4 & 13.2 & 1.4 \\
\hline \multicolumn{5}{|c|}{ handymax (10.5 m) } \\
\hline Full/Down Load & full & down & full & full \\
\hline Cargo weight (t) (appx.) & 28,200 & 37,000 & 30,700 & 20,500 \\
\hline Fuel consumption in voyage $(t)$ & 238 & 79 & 237 & 26 \\
\hline $\mathrm{CO}_{2}$ emission per voyage $(\mathrm{kg})$ & 740,687 & 247,063 & 739,186 & 79,407 \\
\hline $\begin{array}{c}\mathrm{CO}_{2} \text { emission per voyage }(\mathrm{kg} \\
\mathrm{CO}_{2} / \mathrm{t} \text { of cargo) }\end{array}$ & 26.3 & 6.7 & 24.1 & 3.9 \\
\hline $\mathrm{CO}_{2}$ emission $\left(\mathrm{g} \mathrm{CO}_{2} / \mathrm{MJ}\right)$ & 1.66 & 0.42 & 1.36 & 0.43 \\
\hline \multicolumn{5}{|c|}{ panamax $(10.5 \mathrm{~m})$} \\
\hline Full/down load & down & down & down & full \\
\hline Cargo weight (t) (appx.) & 48,500 & 48,500 & 48,500 & 39,000 \\
\hline Fuel consumption in voyage $(t)$ & 515 & 172 & 514 & 55 \\
\hline $\mathrm{CO}_{2}$ emission per voyage $(\mathrm{kg})$ & $1,604,822$ & 535,302 & $1,601,569$ & 172,049 \\
\hline $\begin{array}{c}\mathrm{CO}_{2} \text { emission per voyage }(\mathrm{kg} \\
\mathrm{CO}_{2} / \mathrm{t} \text { of cargo) }\end{array}$ & 33.1 & 11.0 & 33.0 & 4.4 \\
\hline $\mathrm{CO}_{2}$ emission $\left(\mathrm{g} \mathrm{CO}_{2} / \mathrm{MJ}\right)$ & 2.09 & 0.69 & 1.87 & 0.49 \\
\hline \multicolumn{5}{|c|}{ truck } \\
\hline Payload (t) & 25 & 25 & 25 & 25 \\
\hline Road distance $(\mathrm{km})$ & - & 2120 & 2100 & 1250 \\
\hline Fuel consumption in voyage (l) & - & 763.2 & 756 & 450 \\
\hline $\mathrm{CO}_{2}$ emission per voyage $(\mathrm{kg})$ & - & 2014.8 & 1995.8 & 1188.0 \\
\hline $\begin{array}{c}\mathrm{CO}_{2} \text { emission per voyage }(\mathrm{kg} \\
\mathrm{CO}_{2} / \mathrm{t} \text { of cargo) }\end{array}$ & - & 80.6 & 79.8 & 47.5 \\
\hline $\mathrm{CO}_{2}$ emission $\left(\mathrm{g} \mathrm{CO}_{2} / \mathrm{MJ}\right)$ & - & 5.04 & 4.51 & 5.28 \\
\hline \multicolumn{5}{|c|}{ train } \\
\hline Rail distance $(\mathrm{km})$ & - & 2189 & 2338 & 1003 \\
\hline Electrified & - & 2184 & 2338 & 543 \\
\hline Diesel & - & 5 & 0 & 460 \\
\hline $\begin{array}{c}\mathrm{CO}_{2} \text { emission per voyage }(\mathrm{kg} \\
\mathrm{CO}_{2} / \mathrm{t} \text { of cargo) }\end{array}$ & - & 48.2 & 51.4 & 22.1 \\
\hline $\mathrm{CO}_{2}$ emission $\left(\mathrm{g} \mathrm{CO}_{2} / \mathrm{MJ}\right)$ & - & 3.01 & 2.91 & 2.45 \\
\hline
\end{tabular}

Table A1. Carbon footprint data. 


\section{References}

1. European Commission. A European Green Deal. Striving to be the First Climate-Neutral Continent. Available online: https: / / ec.europa.eu/info/strategy/priorities-2019-2024/european-green-deal_en (accessed on 10 December 2020).

2. Scarlat, N.; Dallemand, J.-F.; Taylor, N.; Banja, M.; Lopez, J.S.; Avraamides, M. Brief on Biomass for Energy in the European Union; Publications Office of the European Union: Luxembourg, 2019.

3. European Parliament and Council of the European Union. Directive (EU) 2018/2001 of the European Parliament and of the Council of 11 December 2018 on the Promotion of the Use of Energy from Renewable Sources; European Environment Agency: Copenhagen, Denmark, 2018.

4. Decarb Europe. The Bioenergy Europe Statistical Report 2018. Available online: https://decarbeurope.org/2019/04/01 /bioenergy-europe-report-2018/ (accessed on 10 December 2020).

5. Puigjaner, L.; Pérez-Fortes, M.; Laínez-Aguirre, J.M. Towards a carbon-neutral energy sector: Opportunities and challenges of coordinated bioenergy supply Chains-A PSE approach. Energies 2015, 8, 5613-5660. [CrossRef]

6. Dafnomilis, I.; Lodewijks, G.; Junginger, M.; Schott, D.L. Evaluation of wood pellet handling in import terminals. Biomass Bioenergy 2018, 117, 10-23. [CrossRef]

7. Thrän, D.; Schaubach, K.; Peetz, D.; Junginger, M.; Mai-Moulin, T.; Schipfer, F.; Olsson, O.; Lamers, P. The dynamics of the global wood pellet markets and trade-Key regions, developments and impact factors. Biofuels Bioprod. Biorefining 2019, 13, 267-280. [CrossRef]

8. Port Strategy. Breaking into the Biomass Arena. Available online: https://www.portstrategy.com/ (accessed on 10 December 2020).

9. Wood Pellet Association of Canada. Proper Handling of Wood Pellets. Available online: https://www.pellet.org/wpac-news/ proper-handling-of-wood-pellets (accessed on 10 December 2020).

10. Bijarchiyan, M.; Sahebi, H.; Mirzamohammadi, S. A sustainable biomass network design model for bioenergy production by anaerobic digestion technology: Using agricultural residues and livestock manure. Energy Sustain. Soc. 2020, 10. [CrossRef]

11. Mai-Moulin, T.; Visser, L.; Fingerman, K.R.; Elbersen, W.; Elbersen, B.; Nabuurs, G.J.; Fritsche, U.R.; Del Campo Colmenar, I.; Rutz, D.; Diaz-Chavez, R.A.; et al. Sourcing overseas biomass for EU ambitions: Assessing net sustainable export potential from various sourcing countries. Biofuels Bioprod. Biorefining 2019, 13, 293-324. [CrossRef]

12. Pelkmans, L.; Van Dael, M.; Junginger, M.; Fritsche, U.R.; Diaz-Chavez, R.; Nabuurs, G.J.; Del Campo Colmenar, I.; Gonzalez, D.S.; Rutz, D.; Janssen, R. Long-term strategies for sustainable biomass imports in European bioenergy markets. Biofuels Bioprod. Biorefining 2019, 13, 388-404. [CrossRef]

13. Hoefnagels, R.; Junginger, M.; Resch, G. Coordination of Biomass Resource Availability Import Strategies and Demand; Fraunhofer Institute for Systems and Innovation Research ISI: Karlsruhe, Germany, 2015; Available online: http://www.diacore.eu/images/ files2/Coordination_of_biomass_resource_availability_import_strategies_and_demand.pdf (accessed on 10 December 2020).

14. European Parliament and Council of the European Union. Directive 2009/28/EC of the European Parliament and of the Council of 23 April 2009 on the promotion of the use of energy from renewable sources and amending and subsequently repealing Directives 2001/77/EC and 2003/30/EC. In Directive 2009/28/EC; European Environment Agency: Copenhagen, Denmark, 2009.

15. Proskurina, S.; Rimppi, H.; Heinimö, J.; Hansson, J.; Orlov, A.; Raghu, K.; Vakkilainen, E. Logistical, economic, environmental and regulatory conditions for future wood pellet transportation by sea to Europe: The case of Northwest Russian seaports. Renew. Sustain. Energy Rev. 2016, 56, 38-50. [CrossRef]

16. Sikanen, L.; Korpinen, O.-J.; Tornberg, J.; Saarentaus, T.; Leppänen, K.; Jahkonen, M. Energy Biomass Supply Chain Concepts Including Terminals; Julkaisuvuosi: Helsinki, Finland, 2016; Available online: http://bestfinalreport.fi/files/ EnergyBiomassSupplyChainConceptsIncludingTerminals.pdf (accessed on 15 December 2020).

17. The World Bioenergy Association (WBA). Biomass supply chains. Harvesting and Collection, Pre-Treatment and Upgrading, Storage, Transportation and Handling. 2018. Available online: http://www.worldbioenergy.org/uploads/Factsheet $\% 20-\% 20$ Biomass\%20Supply\%20Chains.pdf (accessed on 15 December 2020).

18. Beagle, E.; Belmont, E. Comparative life cycle assessment of biomass utilization for electricity generation in the European Union and the United States. Energy Policy 2019, 128, 267-275. [CrossRef]

19. Rahman, N.S.F.A.; Ismail, A.; Othman, M.K.; Roslin, R.A.M.; Lun, Y.H.V. Decision making technique for analysing performance of Malaysian secondary ports. Int. J. Shipp. Transp. Logist. 2018, 10, 468-496. [CrossRef]

20. Verhoeven, P. European ports policy: Meeting contemporary governance challenges. Marit. Policy Manag. 2009, 36, 79-101. [CrossRef]

21. Ding, Z.Y.; Jo, G.S.; Wang, Y.; Yeo, G.T. The relative efficiency of container terminals in small and medium-sized ports in China. Asian J. Shipp. Logist. 2015, 31, 231-251. [CrossRef]

22. Feng, L.; Notteboom, T. Peripheral challenge by small and medium sized ports (SMPs) in multi-port gateway regions: The case study of northeast of China. Pol. Marit. Res. 2013, 20, 55-66. [CrossRef]

23. Mańkowska, M.; Kotowska, I.; Pluciński, M. Seaports as nodal points of circular supply chains: Opportunities and challenges for secondary ports. Sustainability 2020, 12, 3926. [CrossRef]

24. Wróbel, P.; Ścigan, M. Cel OZE Na 2020: Co Się Stanie, Jeśli Polska Go Nie Osiagnie? Centrum Informacji o Rynku Energii: Warsaw, Poland, 2020; Available online: https: / www.cire.pl/item,195211,13,11,12,0,344176,0,cel-oze-na-2020-co-sie-stanie-jesli-polskago-nie-osiagnie.html\#komentarz (accessed on 20 December 2020). (In Polish) 
25. Ścigan, M.; Jędra, M. OZE W Polskim Miksie. Wciąż Za Mało, By Wypetnić Cele; Centrum Informacji o Rynku Energii: Warsaw, Poland; Available online: https: / / www.cire.pl/item,201824,13,0,0,0,0,0,oze-w-polskim-miksie-wciaz-za-malo-by-wypelnic-cele.html (accessed on 20 December 2020). (In Polish)

26. Fingerman, K.R.; Nabuurs, G.J.; Iriarte, L.; Fritsche, U.R.; Staritsky, I.; Visser, L.; Mai-Moulin, T.; Junginger, M. Opportunities and risks for sustainable biomass export from the south-eastern United States to Europe. Biofuels Bioprod. Biorefining 2017, 13, 281-292. [CrossRef]

27. Michalski, K.; Navickas, M.; Rabe, M. Transport in the biomass supply chain for a power plant. Ekon. Organ. Logistyk 2019, 4, 17-27. [CrossRef]

28. Racz, K.; Wilde-Ramsing, J.; Van Seters, J.; Scheele, F. From whence the wood? Supply chain transparency and the origin of solid biomass for electricity generation in The Netherlands. SSRN Electron. J. 2013. [CrossRef]

29. Lamers, P.; Hoefnagels, R.; Junginger, M.; Hamelinck, C.; Faaij, A. Global solid biomass trade for energy by 2020: An assessment of potential import streams and supply costs to North-West Europe under different sustainability constraints. GCB Bioenergy 2015, 7, 618-634. [CrossRef]

30. Liu, Z.; Wang, S.; Ouyang, Y. Reliable biomass supply chain design under feedstock seasonality and probabilistic facility disruptions. Energies 2017, 10, 1895. [CrossRef]

31. Acciaro, M.; Ghiara, H.; Cusano, M.I. Energy management in seaports: A new role for port authorities. Energy Policy 2014, 71, 4-12. [CrossRef]

32. Wang, W.; Ouyang, W.; Hao, F. A supply-chain analysis framework for assessing densified biomass solid fuel utilization policies in China. Energies 2015, 8, 7122-7139. [CrossRef]

33. Latterini, F.; Stefanoni, W.; Suardi, A.; Alfano, V.; Bergonzoli, S.; Palmieri, N.; Pari, L. A GIS approach to locate a small size biomass plant powered by olive pruning and to estimate supply chain costs. Energies 2020, 13, 3385. [CrossRef]

34. Cambero, C.; Sowlati, T. Assessment and optimization of forest biomass supply chains from economic, social and environmental perspectives-A review of literature. Renew. Sustain. Energy Rev. 2014, 36, 62-73. [CrossRef]

35. Atashbar, N.Z.; Labadie, N.; Prins, C. Modelling and optimisation of biomass supply chains: A review. Int. J. Prod. Res. 2018, 56, 3482-3506. [CrossRef]

36. Ba, B.H.; Prins, C.; Prodhon, C. Models for optimization and performance evaluation of biomass supply chains: An operations research perspective. Renew. Energy 2016, 87, 977-989. [CrossRef]

37. Stevens, L.C.E.; Vis, I.F.A. Port supply chain integration: Analyzing biofuel supply chains. Marit. Policy Manag. 2016, 43, 261-279. [CrossRef]

38. Yin, R.K. Case Study Research and Applications; Sage Publications: Thousand Oaks, CA, USA, 2018.

39. Andersen, P.H.; Dubois, A.; Lind, F. Process validation: Coping with three dilemmas in process-based single-case research. J. Bus. Ind. Mark. 2018, 33, 539-549. [CrossRef]

40. The Szczecin and Świnoujście Seaports Authority. 2019. Available online: https://www.port.szczecin.pl/en/news/2019/ (accessed on 20 December 2020).

41. Guion, L.A. Conducting an In-depth Interview. Boards 2006, 1-4.

42. Kvale, S. Interviews: An Introduction to Qualitative Research Interviewing, 1st ed.; Sage Publications: Thousand Oaks, CA, USA, 1996.

43. Fülöp, J. Introduction to Decision Making Methods; BDEI-3 Workshop; Citeseer: Washington, DC, USA, 2005; pp. 1-15. Available online: https: / / citeseerx.ist.psu.edu/viewdoc/download?doi=10.1.1.86.6292\&rep=rep1\&type=pdf (accessed on 20 December 2020).

44. McCormack, C. Storying stories: A narrative approach to in-depth interview conversations. Int. J. Soc. Res. Methodol. 2004, 7, 219-236. [CrossRef]

45. Krantz, G. $\mathrm{CO}_{2}$ and Sulphur Emissions from the Shipping Industry; Trans Oleum: Stockholm, Sweden, 2016.

46. Delgado, O.; Rodriguez, F.; Muncrief, R. Fuel Efficiency Technology in European Heavy-Duty Vehicles: Baseline and Potential for the 2020-2030 Timeframe; International Council on Clean Transportation: Berlin, Germany, 2017.

47. Cefic. Guidelines for Measuring and Managing CO2 Emission from Freight Transport Operations; Cefic: Brussels, Belgium, 2011.

48. Ministry of Climate and Environment of the Republic of Poland. The Energy Policy for Poland 2040 Project; Monitor Polski: Warsaw, Poland, 2020. (In Polish)

49. Ustawa z dnia 20 lutego 2015 r. o odnawialnych źródłach energii, Dz.U. 2020 poz. 261. Available online: http:/ /isap.sejm.gov.pl/ isap.nsf/DocDetails.xsp?id=WDU20200000261 (accessed on 20 December 2020). (In Polish)

50. Ministry of State Assets of the Republic of Poland. Poland's National Energy and Climate Plan for The Years 2021-2030; Ministry of State Assets of the Republic of Poland: Warsaw, Poland, 2019. (In Polish) 